\title{
High-Resolution Profiles of Dissolved Reactive Phosphorus in the Porewaters of Lake Sediments Assessed by DGT Technique
}

\author{
Jian Wang1,2, Jingtian Zhang², Qiong Xie², Fengyu Zan'1,2, Shengpeng Zuo', Shouliang Huo ${ }^{2 *}$ \\ ${ }^{1}$ College of Environmental Science and Engineering, Anhui Normal University, Wuhu, China \\ ${ }^{2}$ State Key Laboratory of Environmental Criteria and Risk Assessment, Chinese Research Academy of \\ Environmental Science, Beijing, China \\ Email: ${ }^{\text {huoshouliang@126.com }}$
}

Received 24 April 2014; revised 17 May 2014; accepted 4 June 2014

Copyright @ 2014 by authors and Scientific Research Publishing Inc.

This work is licensed under the Creative Commons Attribution International License (CC BY). http://creativecommons.org/licenses/by/4.0/

(c) (i) Open Access

\section{Abstract}

The technique of DGT (diffusive gradients in thin films) was applied to obtain high-resolution vertical profiles of dissolved reactive phosphorus (DRP) in sediment porewater of Lake Chaohu, a shallow eutrophication lake. Three kinds of DGT probes (with three thicknesses of diffusive gel: $0.38 \mathrm{~mm}, 0.78 \mathrm{~mm}$ and $1.18 \mathrm{~mm}$ ) measured vertical concentration and induced flux from solid to solution phase which had intricate variations with depth. The results indicated that higher concentrations and induced fluxes of DRP were achieved by using DGT probe with thicker diffusion layer ( $\mathrm{C}_{\mathrm{DGT1} 1.18}>\mathrm{C}_{\mathrm{DGT} \text {.78 }}>\mathrm{C}_{\mathrm{DGT}}$.38) and relatively stable DRP concentration profiles using DGT probes with $0.78 \mathrm{~mm}$ diffusive gel were obtained in each sediment core. The DRP concentrations displayed a clear gradient from Core $\mathrm{C} 1$ to Core $\mathrm{C} 3$ in sediment porewaters due to different sources and exchange degrees of reactive phosphorus. Compared to the concentrations obtained by the centrifugation technique, the concentrations of DRP resulting from the DGT technique were higher because some dissolved reactive phosphorus compounds have always been neglected using conventional centrifugation method.

\section{Keywords}

Dissolved Reactive Phosphorus (DRP), Diffusive Gradients in Thin Films (DGT) Technique, Porewaters, Sediments

\footnotetext{
"Corresponding author.
}

How to cite this paper: Wang, J., Zhang, J.T., Xie, Q., Zan, F.Y., Zuo, S.P. and Huo, S.L. (2014) High-Resolution Profiles of Dissolved Reactive Phosphorus in the Porewaters of Lake Sediments Assessed by DGT Technique. Journal of Environmental Protection, 5, 694-702. http://dx.doi.org/10.4236/jep.2014.58070 


\section{Introduction}

Sediments have received large amounts of phosphorus, including inorganic species (e.g. mono- or diprotonated orthophosphate) and organic species (e.g. DNA-P, P-lipids, Teichoic-P) [1] [2]. Phosphorus fractions could transfer and transform between the solid phase (i.e. sediment) and the water column (i.e. porewaters, overlying water) by microbial activities and diffusion with the variation of redox conditions [3] [4]. Dissolved reactive phosphorus (DRP) is the predominant inorganic species which is bioavailable for algae and other phytoplankton according to its abundance and dynamics [1]. Thus, it is necessary to carry out related studies to understand the distribution of DRP and clarify the release mechanism of DRP in the porewaters of lake sediment.

DRP is an operational definition for soluble phosphate which passes a $0.45 \mu \mathrm{m}$ filter and can be measured colorimetrically [5] [6]. However, some inorganic condensed phosphorus (e.g. pyrophosphate, tripolyphosphate, trimetaphosphate) may easily pass a $0.45 \mu \mathrm{m}$ filter which is bioavailable for algae [7]. Therefore, DRP could be underestimated because only orthophosphate is determined by this method. Additionally, in aquatic sediments, the permanent anoxic conditions in porewaters may interfere with SRP analysis during sampling and pretreatment [8]. The conventional methods of squeezing, coring and centrifugation may destroy the anoxic conditions and introduce the biases. The diffusive gradient in thin films (DGT) technique is an in situ analytical method that is designed to accumulate labile species (e.g. metals, sulfide, phosphorus) in environmental systems [7] [9] [10]. DGT in situ accumulates these species on a binding gel after they freely transport through a diffusive layer and $0.45 \mu \mathrm{m}$ filter membrane. More than 95\% recovery and high capacities were obtained for these labile species determination using DGT [11] [12].

Recently, the DGT technique has been applied to the in situ measurements of the DRP in natural waters [7] [13] [14]. Phosphorus species diffuse through a layer of polyacrylamide gel and then bind to ferrihydrite embedded in a further layer of gel. However, research on DRP measurements in sediment porewaters using DGT has not been adequately carried out. For DRP determination in sediment porewaters, DGT is superior to other sampling methods in that it accumulates chemicals continuously from both the solution and solid phases, and can provide time-weighted average concentration over the exposure period based on Fick's first law of diffusion [15] [16]. Moreover, DGT measures both inorganic and labile organic species, which are the bioavailable phosphorus forms [17]. Therefore, this technology has been successfully applied to sediment porewaters for DRP measurement [18] [19]. Fe-Oxide is a traditional binding gel for liable and available phosphorus fractions with high precision and accuracy. Recently, Zr-Oxide is developed as a new binding gel due to high selectivity and great capcacity for absorbing phosphate [12] [20]. In this work, DGT is used to measure DRP concentration in porewaters of Lake Chaohu to provide in situ data of the induced flux and concentration profile. Three kinds of DGT probes (with diffusive gel: $0.38 \mathrm{~mm}, 0.78 \mathrm{~mm}$ and $1.18 \mathrm{~mm}$ ) were used. The aim of this experiment is to investigate the horizontal and vertical distribution of DRP in sediment porewaters of Lake Chaohu and to estimate the diffusive boundary layer thickness in the performance of DGT. Moreover, the reproducibility and accuracy of the operation, the capacity of the solid phase to resupply solute to porewater were also analyzed.

\section{Materials and Methods}

\subsection{Study Area}

Lake Chaohu is a shallow, eutrophic lake, with a surface area of $780 \mathrm{~km}^{2}$, a mean depth of $c a 3.0 \mathrm{~m}$ and a catchment area of 12,938 $\mathrm{km}^{2}$. The western region ( $\mathrm{ca} 1 / 3$ of area) is surrounded by Heifei (the capital city of Anhui Province) and the eastern region ( $c$ a 2/3 of area) by Chaohu City. Eight main rivers, which provide about $90 \%$ of the runoff volume from the catchment area, feed Lake Chaohu and the outlet, the Yuxi River, is the only channel linking the lake to the Yangtze River (Figure 1). The lake has suffered from serious eutrophication in recent years, caused by wastewater and agricultural runoff from Hefei and Chaohu cities [21]. The sedimentary input of most nutrients began to increase at around 1950, and nutrient loading has accelerated since the 1960 s. Furthermore, nutrient loading has accelerated since the 1970s because of the large amount of industrial, agricultural and domestic sewage discharged into the lake [21] [22]. Inorganic phosphorus dominated all sediment samples, accounting for 73.96\% of total phosphorus in Lake Chaohu [23] [24].

\subsection{Sediment Samples and Analysis}

The core sediment samples were collected in March 2013, in three defined sampling positions in Lake Chaohu 


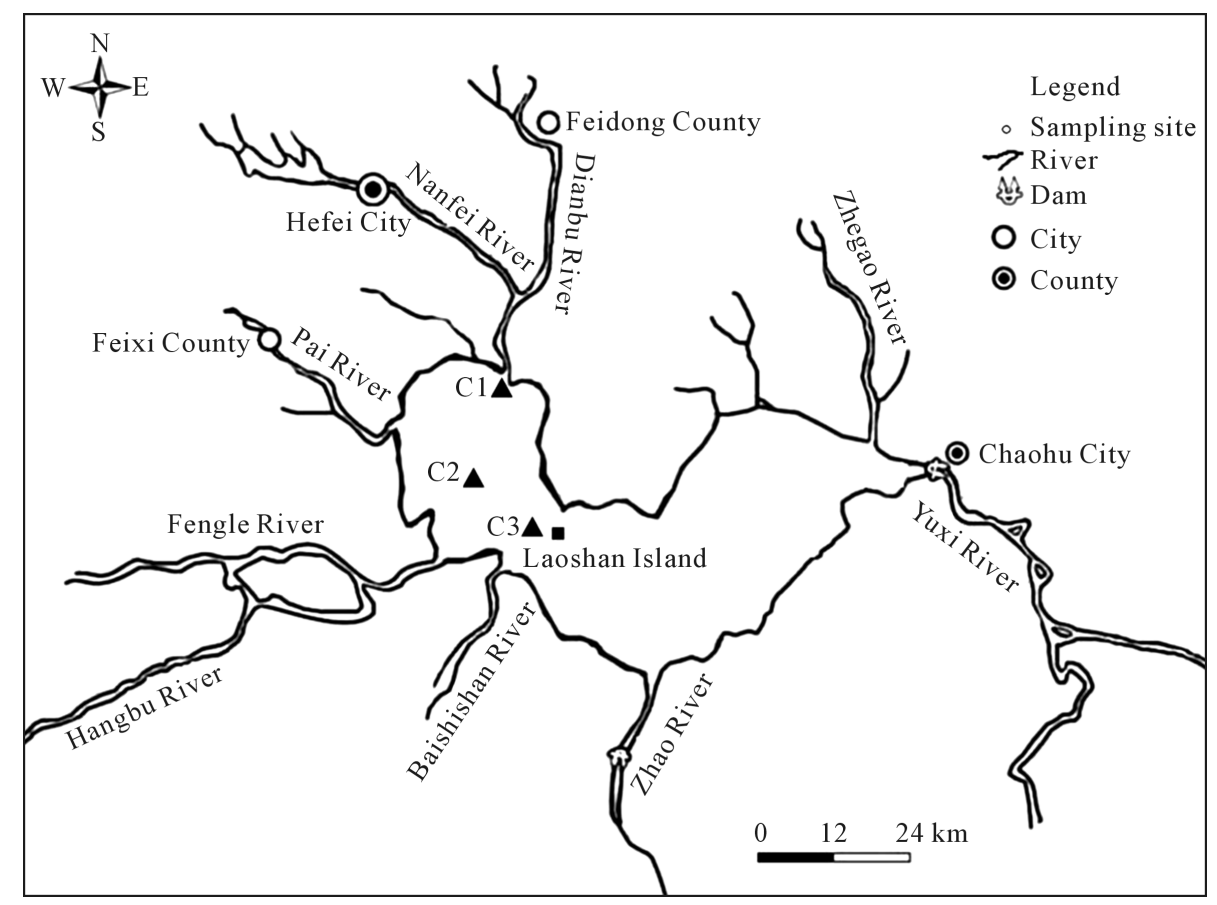

Figure 1. Sampling sites in lake Chaohu (C1-C3).

(Figure 1). As it is shown in Figure 1, the C1 site is located near the entrance of Nanfei River, C2 site is located in the central of western half-lake, C3 site is located in the central of the lake near Laoshan Island. Four replicate $30 \mathrm{~cm}$ sediment cores were obtained from every site using a hand driven steel corer with a length of $50 \mathrm{~cm}$ and an internal diameter of $8 \mathrm{~cm}$. Three core sediment samples were treated by three kinds of pretreated DGT probes (with diffusive gel: $0.38 \mathrm{~mm} ; 0.78 \mathrm{~mm} ; 1.92 \mathrm{~mm}$ ). Another core sediment samples were cut and treated with centrifugation followed by a filtration.

\subsection{DGT Technique}

\subsubsection{DGT Preparation}

The DGT device was first described in details by Zhang and Davision (1995) from DGT Research Ltd, Lancaster, England [25]. This technique could measure directly the mean flux of labile species to the device based on Fick's first law of diffusion. The DGT probe is composed of top plastic cover, filter membrane in the first layer, diffusive gel in the second layer, binder gel in the third layer, filter membrane in the fourth layer and bottom plastic holder. The filter membrane (thickness: $0.13 \mathrm{~mm}$ ) is used to prevent plankton and small particles with the diameter larger than $0.45 \mu \mathrm{m}$. The diffusive gel (which has controlled porosity) serves to provide a constant concentration gradient during diffusion of the DRP between the porewaters and the binding gel. Fe-oxide is a binding material and it would cause the DRP to be rapidly and irreversibly removed from porewaters. The mass of DRP accumulated in the Fe-Oxide gel is measured on retrieval, and Fick's first law of diffusion is used to calculate the in situ DRP concentration in porewaters. Three kinds of diffusive gel (with thickness: $0.38 \mathrm{~mm}$, $0.78 \mathrm{~mm}$ and $1.18 \mathrm{~mm}$ ) were prepared. The same length of $150 \mathrm{~mm}$ was obtained in each gel (i.e. filter membrane, diffusive gel and binder gel). The probes were deoxygenated by immersing them in $0.01 \mathrm{M} \mathrm{NaCl}$ bubbled with high-purity nitrogen for $24 \mathrm{~h}$ to avoid any introduction of oxygen to the sediment during operation before laboratory deployment.

\subsubsection{DGT Operation and Treatment}

Deployments were carried out immediately after the core sediment samples were transported into the laboratory. Three DGT probes (with thickness: $0.38 \mathrm{~mm}, 0.78 \mathrm{~mm}$ and $1.18 \mathrm{~mm}$ ) were inserted into three core sediments respectively. The probes were pushed gently and smoothly until the top of the gel was in line with sedimentwater interface. The temperature $\left(16^{\circ} \mathrm{C}\right)$ and the time of deployment were noted down. After $24 \mathrm{~h}$ exposure in 
porewaters, the probes were pull out from the sediment and the probe surfaces were rinsed with Millipore water to avoid preservation of the particles on the surface of probes. Then, the binding gel was removed from the DGT assembly and cut into $5 \mathrm{~mm} \times 18 \mathrm{~mm}$ segments using a Teflon coated blade. Each segment was put into a centrifuge vial $(0.50 \mathrm{ml})$ and $0.80 \mathrm{ml}$ of $0.25 \mathrm{M} \mathrm{H}_{2} \mathrm{SO}_{4}$ solution was added to elute DRP binding with Fe-Oxide gel. The samples were diluted twice for DRP determination.

\subsubsection{Calculation Procedures}

A detailed description of DGT calculation procedures was given by Zhang et al., 1995 [25]. The mass of DRP in the binding gel (M) can be calculated using Equation (1)

$$
M=C_{e}\left(V_{\text {acid }}+V_{\text {gel }}\right) / f_{e}
$$

where $C_{e}$ is the concentration of DRP in the $0.25 \mathrm{M} \mathrm{H}_{2} \mathrm{SO}_{4}$ elution solution (in $\mu \mathrm{g} / \mathrm{l}$ ), $V_{\text {acid }}$ is the volume of $0.25 \mathrm{M} \mathrm{H}_{2} \mathrm{SO}_{4}$ added to the Fe-Oxide gel, $V_{\text {gel }}$ is the volume of Fe-Oxide gel, $f_{e}$ is the elution factor for DRP, which is 1 in this case.

The fluxes $(\mathrm{F})$ induced by $\operatorname{DGT}\left(C_{\mathrm{DGT}}\right)$ can be calculated using Equation (2)

$$
C_{\text {DGT }}=M \Delta g /(D t A)
$$

where $\Delta g$ is the thickness of the diffusive gel $(0.38 \mathrm{~mm}, 0.78 \mathrm{~mm}, 1.18 \mathrm{~mm})$ plus the thickness of the filter membrane $(0.13 \mathrm{~mm}), D$ is the diffusion coefficient of $\mathrm{P}$ in the gel, which is $3.87 \times 10^{-6} \mathrm{~cm}^{2} / \mathrm{s}$ at $10^{\circ} \mathrm{C}, t$ is the deployment time and $\mathrm{A}$ is the exposure area $\left(A=0.9 \mathrm{~cm}^{2}\right)$.

\subsection{Conventional Centrifugation}

Another core sediment samples were cut at $1 \mathrm{~cm}$ intervals and collected in sealed polyethylene tubes under a nitrogen atmosphere. Then the sediment sub-samples were centrifuged at $8000 \mathrm{rpm}$ for 10 min to separate out porewaters into $10 \mathrm{ml}$ vials. The porewaters samples were filtered by $0.45 \mu \mathrm{m}$ cellulose acetate membrane and kept at $4^{\circ} \mathrm{C}$ for analysis. Dissolved reactive phosphorus (DRP) in samples was determined using molybdenum blue method with Discrete Auto Analyzer (SmartChem 200, Alliance, France). The limit of detection of this method was $0.01 \mathrm{mg}$ P/L. TOC was measured using a TOC analyzer (Multi N/C 2100, AnalytikJena, Germany).

\section{Results and Discussion}

\subsection{DRP Concentrations in Vertical Sediment Porewater Profiles}

The DRP profiles in porewaters determined by DGT with three thicknesses of diffusive gels are presented in Figure 2. DRP concentrations in the deep plot were mostly above $0.01 \mathrm{mg} / \mathrm{L}$ with $0.38 \mathrm{~mm}$ diffusive gel, 0.02 $\mathrm{mg} / \mathrm{L}$ with $0.78 \mathrm{~mm}$ diffusive gel, $0.03 \mathrm{mg} / \mathrm{L}$ with $1.18 \mathrm{~mm}$ diffusive gel. The trend of DRP concentrations in the profile was the same as average DRP concentration determined by DGT with different diffusive gel thickness, which indicated relatively higher phosphorus transferred from solid phrase of sediment to porewater in the profile using DGT with thicker diffusive gel. Similar results for Fe, Mn, Co and Cd concentration profiles in porewaters were found by Wu et al. (2011) [26]. The DRP concentrations obtained from DGT probes with different diffusive thicknesses showed useful information on phosphorus behavior at a millimetric scale in porewaters. In each sample site, DRP measured by DGT represented the average concentration over the deployment time, therefore the DGT-DRP distributions record the process information of phosphorus exchange between sediments and porewaters. For the $\mathrm{DGT}_{0.38}$, DRP concentrations in the profiles were much smaller than those for $\mathrm{DGT}_{0.78}$ and $\mathrm{DGT}_{1.18}$, which indicated phosphorus in porewaters were partially diffused and fixed in the Fe-Oxide gel [25]. For the $\mathrm{DGT}_{0.78}$, DRP concentrations were relatively stable and similar variation trend was presented in the profiles of each site. Generally, this probe should be chosen as the deployment probe in practical application [25]. For the $\mathrm{DGT}_{1.18}$, DRP profiles showed larger amplitude in concentrations than those for $\mathrm{DGT}_{0.38}$ and $\mathrm{DGT}_{0.78}$, which indicated more DRP transported from sediment to porewaters with thicker diffusive gel. In general, phosphorus is free to diffuse vertically along concentration gradients before being fixed by FeOxide gel; very steep porewaters gradients would be also present due to lateral diffusion, especially for thicker diffusion layers [27] [28]. Therefore, smoothing sharp features was more pronounced to form for the DGT probes with $1.18 \mathrm{~mm}$ diffusive gel in the profiles. 


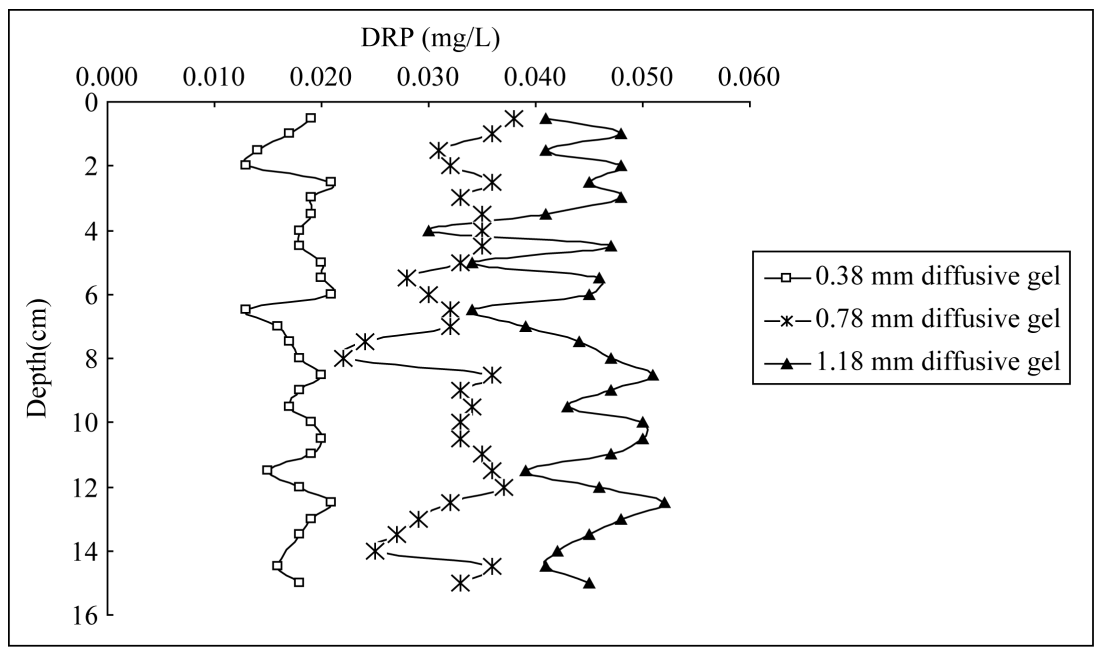

(a)

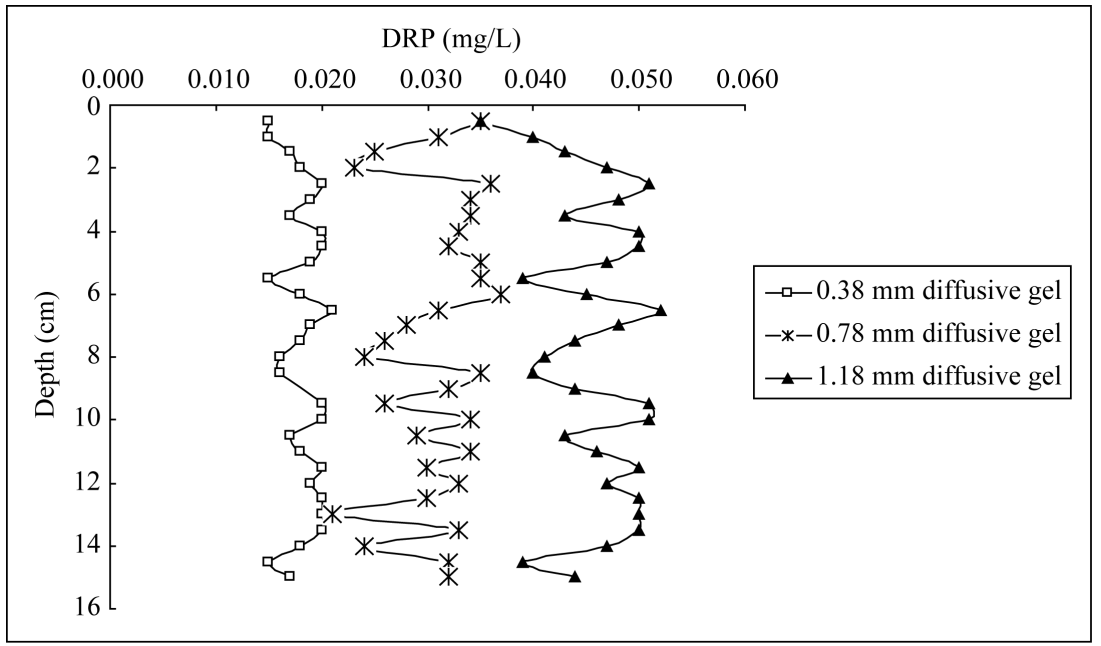

(b)

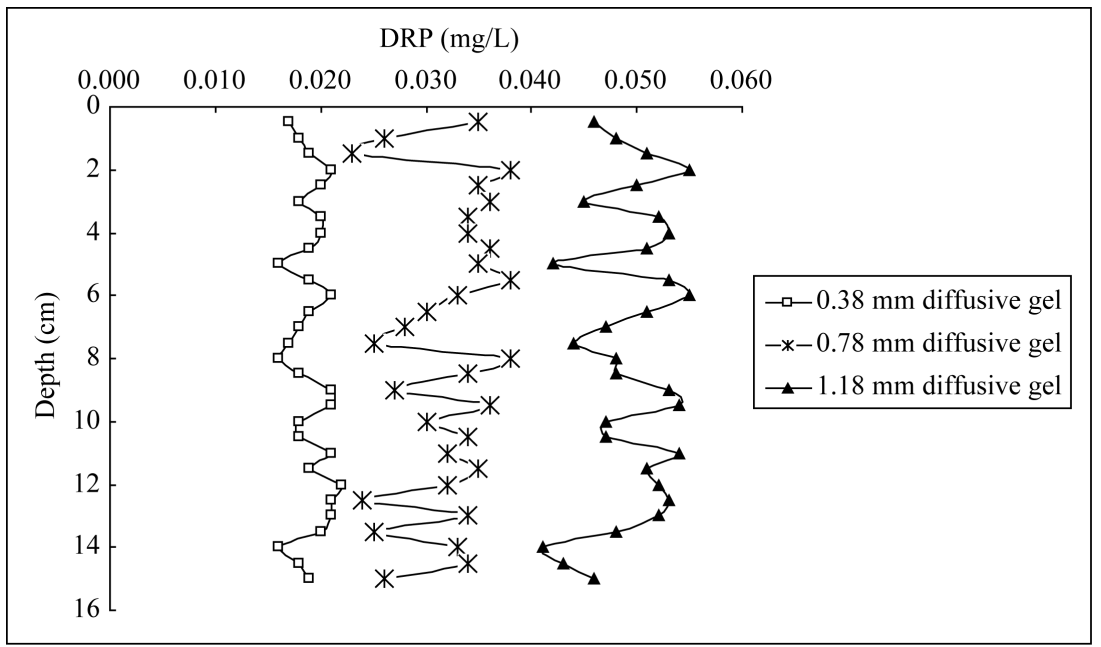

(c)

Figure 2. Vertical profiles of DRP concentrations in sediment porewater of Lake Chaohu: (a) Core C1, (b) Core C2, (c) Core C3. 
DRP profiles in core C1 varied significantly especially for the DGT with $1.18 \mathrm{~mm}$ diffusive gel and more than two concentration peaks were observed. For $\mathrm{DGT}_{0.38}$ and $\mathrm{DGT}_{0.78}$, the first concentration peak appear at $2.5 \mathrm{~cm}$ layer with $0.021 \mathrm{mg} / \mathrm{l}$ and $0.036 \mathrm{mg} / \mathrm{l}$, respectively, the second concentration peak appear at $8.5 \mathrm{~cm}$ layer with $0.020 \mathrm{mg} / \mathrm{l}$ and $0.036 \mathrm{mg} / \mathrm{l}$, respectively, which were consistent with the phosphorus pollution history in the sediments since 2000s and 1980s, respectively [22]. DRP concentration peaks in the profile can be generated from different sources where diffusional transport can occur in three dimensions [29]. The principal phosphorus pollutant inflow to the region comes from the Nanfei River that discharges untreated domestic and industrial wastewater from Hefei City. The phosphorus loading has accelerated since the 1980s as a consequence of the large amounts of industrial, agricultural and domestic sewages discharged into Chaohu Lake [22] [24].

DRP profiles determined by the DGT probes with three different diffusive thicknesses in core C2 were similar with those in core C3, which indicated that similar phosphorus pollution in the two sites has been recorded during the past 50 years. C2 site is located in the central of western half-lake, C3 site is located in the central of the lake near Laoshan Island. Agricultural activities are the main external phosphorus source in the two sites, and uniformly mixing conditions contribute similar endogenous phosphorus deposition due to the construction of the dam since 1960s [21]. For C2 and C3, there was a systematic increase of DRP concentrations in $\mathrm{DGT}_{0.38}$ and DGT $_{1.18}$ profiles at the depth of $0-2.5 \mathrm{~cm}$ and $0-2.0 \mathrm{~cm}$, respectively. In the first decade of this century, majority of phosphorus was discharged into Lake Chaohu and deposited into sediments with the rapid agricultural development. It was reported that phosphorus deposited into sediments was adsorbed in aerobic conditions by hydroxides and oxides of Fe and Mn, and was released into porewaters in anaerobic conditions by reduction of hydroxides and oxides of Fe and Mn [30] [31].

\subsection{Comparison of the DRP Concentration Using Centrifugation and DGT Methods}

The DRP concentrations in the porewaters of sediment cores using DGT and centrifugation measurements were shown in Table 1. The average DRP concentrations measured by centrifugation were lower than those determined by DGT with diffusive gels of $0.78 \mathrm{~mm}$ and $1.18 \mathrm{~mm}$ thicknesses, but higher than those determined by DGT with thickness of $0.38 \mathrm{~mm}$. The results indicated that some inorganic condensed phosphorus (e.g. pyrophosphate, tripolyphosphate, trimetaphosphate) and micro-molecular organic P compounds were also adsorbed by Fe-oxide gel during the deployment of DGT [32]. These dissolved reactive phosphorus compounds could be hydrolyzed into orthophosphate by $\mathrm{H}_{2} \mathrm{SO}_{4}$ in the elution step of DGT methods, and be determined by traditional molybdenum blue method. Although measurements using ${ }^{31} \mathrm{P}$ NMR indicated that the phosphorus species in sediments of seven freshwater lakes were dominated by orthophosphate, other phosphorus fractions (e.g. orthophosphate diesters and monoesters, pyrophosphate) represented nearly $20 \%$ of the total dissolved phosphorus [33]. The fractions of DRP have always been neglected when measured DRP in sediment porewaters using conventional centrifugation method. DGT is a high resolution in situ measurement method, thus the fractions of inorganic condensed phosphorus and micro-molecular organic $\mathrm{P}$ are not negligible. Furthermore, there is re-supply process from the solid to porewater using DGT probes with thick diffusive gels, while centrifugation treatment may solely separate phosphorus in porewaters [15] [16]. Therefore, the average DRP concentration using the centrifugation procedure is much lower than those using DGT probes with diffusive gels of $0.78 \mathrm{~mm}$ and 1.18 $\mathrm{mm}$ thicknesses. Similar results for Fe and Mn concentrations in sediment porewaters using DGT and centrifugation were found by Lesven et al. (2008) [34]. The process of inserted DGT probe may deplete porewaters concentrations adjacent to the probe, the interfacial concentration will therefore be less than the bulk porewaters

Table 1. Comparison of the DRP concentration using centrifugation and DGT methods.

\begin{tabular}{|c|c|c|c|c|}
\hline \multirow{3}{*}{ Sampling position } & \multicolumn{4}{|c|}{ Average value of DRP(mg/L) } \\
\hline & \multicolumn{3}{|c|}{ DGT } & \multirow{2}{*}{ Centrifugation } \\
\hline & $0.38 \mathrm{~mm}$ & $0.78 \mathrm{~mm}$ & $1.18 \mathrm{~mm}$ & \\
\hline $\mathrm{C} 1$ & $0.018 \pm 0.002$ & $0.032 \pm 0.004$ & $0.044 \pm 0.005$ & $0.022 \pm 0.014$ \\
\hline $\mathrm{C} 2$ & $0.018 \pm 0.002$ & $0.031 \pm 0.004$ & $0.046 \pm 0.004$ & $0.017 \pm 0.015$ \\
\hline C3 & $0.019 \pm 0.002$ & $0.032 \pm 0.004$ & $0.049 \pm 0.004$ & $0.010 \pm 0.009$ \\
\hline
\end{tabular}


concentration, especially for the DGT probes with thin diffusive gel [28] [35].

For the three sediment cores, the order of average DRP concentration determined by DGT with different diffusive thicknesses was: $\mathrm{DGT}_{1.18 \mathrm{~mm}}>\mathrm{DGT}_{0.78 \mathrm{~mm}}>\mathrm{DGT}_{0.38 \mathrm{~mm}}$, indicating the low DRP diffusion velocity when DGT devices have a thin diffusive layer [36]. According to classical diffusive theory, solute diffusion process in fluid media contains advection and diffusion fractions. It is widely recognized that only diffusion process is present during the process of contaminant dissolution in porewaters due to low advection velocity in porewaters. When DGT probe is immersed in sediment, the transport of phosphorus undergoes a rapid transition from advective to diffusive control in the region close to DGT window [37]. This layer is known as diffusive boundary layer (DBL), and DBL may interfere the formation of DRP diffusive gradients, because DRP is solely transported by molecular diffusion in DBL [14]. The thickness of this layer will be dependent on the flow and the deployment geometry and will effectively extend $\Delta g$ from the window of DGT device out into the bulk solution. The flow velocity in porewaters is much lower than that in surface water, and amount of particulate matters are present in porewaters. Deployment of DGT devices with different diffusive thicknesses showed that the thickness of the DBL was $\sim 0.23 \mathrm{~mm}$ in moderate to well-stirred solutions [38], thus the DBL thickness is not negligible using DGT in porewaters with $0.38 \mathrm{~mm}$ diffusive gel.

\section{Conclusion}

The DGT technique provided an in situ means of measuring DRP in a sediment/water system by a controlled, quantitatively defined way. Well-defined laboratory systems were used to ensure the reproducibility and accuracy of the DGT technique for DRP measurements in sediment porewaters. The higher concentrations and induced fluxes of DRP from sediments to porewaters were obtained with thicker diffusive gel and DGT probes with $0.78 \mathrm{~mm}$ diffusive gel were stable and more appropriate for DRP measurement in sediment porewaters. The DRP concentrations increased from $0 \mathrm{~cm}$ to $2.5 \mathrm{~cm}$ in each sediment core; it was consistent with the rapid economic development of Hefei city in the recent decade. The DRP concentrations displayed a clear gradient from Core C1 to Core C3 in sediment porewaters, indicating a more mass of phosphorus input in the entrance of Nanfei river that received large phosphorus in municipal and industrial wastewater from Hefei city in recent fifty years. Compared to the concentrations obtained by the centrifugation technique, the concentrations of DRP resulting from the DGT technique were higher. That indicated more reactive phosphorus fractions that could be hydrolyzed by $\mathrm{H}_{2} \mathrm{SO}_{4}$ were transported from sediments to porewaters.

\section{Acknowledgements}

This study is supported by the Mega-projects of Science Research for Water Environment Improvement (Program No.2012ZX07101-002), the China Environmental Public Welfare Program (201209014) and the National Natural Science Foundation of China (No. 41303085).

\section{References}

[1] Worsfold, P.J., Monbet, P., Tappin, A.D., Fitzsimons, M.F., Stiles, D.A. and Mckelvie, I.D. (2008) Characterisation and Quantification of Organic Phosphorus and Organic Nitrogen Components in Aquatic Systems: A Review. Analytica Chimica Acta, 624, 37-58. http://dx.doi.org/10.1016/j.aca.2008.06.016

[2] Ahlgren, J., Reitzel, K., Brabandere, H.D., Gogoll, A. and Rydin, E. (2011) Release of Organic P Forms from Lake Sediments. Water Research, 45, 565-572. http://dx.doi.org/10.1016/j.watres.2010.09.020

[3] Li, Y.Z., Xia, B.C., Zhang, J.Y., Li, C.H. and Zhu, W.Z. (2010) Assessing High Resolution Oxidation-Reduction Potential and Soluble Reactive Variation across Vertical Sediments and Water Layers in Xinghu Lake: A Novel Laboratory Approach. Journal of Environmental Sciences, 22, 982-990. http://dx.doi.org/10.1016/S1001-0742(09)60208-4

[4] Gachter, R. and Muller, B. (2003) Why the Phosphorus Retention of Lakes Does Not Necessarily Depend on the Oxygen Supply to Their Sediment Surface. Limnology and Oceanography, 48, 929-933. http://dx.doi.org/10.4319/10.2003.48.2.0929

[5] Karthikeyan, S., Hashigaya, S., Kajiya, T. and Hirata, S. (2004) Determination of Trace Amounts of Phosphate by Flow-Injection Photometry. Analytical and Bioanalytical Chemistry, 378, 1842-1846. http://dx.doi.org/10.1007/s00216-004-2501-9

[6] Davenport, E.S., Shull, D.H. and Devol, A.H. (2012) Roles of Sorption and Tube-Dwelling Benthos in the Cycling of Phosphorus in Bering Sea Sediments. Deep Sea Research Part II: Topical Studies in Oceanography, 65-70, 163-172. 
[7] Zhang, H., Davison, W., Gadi, R. and Kobayashi, T. (1998) In Situ Measurement of Dissolved Phosphorus in Natural Waters Using DGT. Analytica Chimica Acta, 370, 29-38. http://dx.doi.org/10.1016/S0003-2670(98)00250-5

[8] Gillan, D.C., Baeyens, W., Bechara, R., Billon, G., Denis, K., Grosjean, P., Leermakers, M., Lesven, L., Pede, A., Sabbe, K. and Gao, Y. (2012) Links between Bacterial Communities in Marine Sediments and Trace Metal Geochemistry as Measured by in Situ DET/DGT Approaches. Marine Pollution Bulletin, 64, 353-362. http://dx.doi.org/10.1016/j.marpolbul.2011.11.001

[9] Denney, S., Sherwood, J. and Leyden, J. (1999) In Situ Measurements of Labile Cu, Cd and Mn in River Waters Using DGT. The Science of the Total Environment, 239, 71-80. http://dx.doi.org/10.1016/S0048-9697(99)00304-6

[10] Devries, C.R. and Wang, F.Y. (2003) In Situ Two-Dimensional High-Resolution Profiling of Sulfide in Sediment Interstitial Waters. Environmental Science and Technology, 37, 792-797. http://dx.doi.org/10.1021/es026109j

[11] Teasdale, P. R., Hayward, S. and Davison, W. (1999) In Situ, High-Resolution Measurement of Dissolved Sulfide Using Diffusive Gradients in Thin Films with Computer-Imaging Densitomery. Analytical Chemistry, 71, 2186-2191. http://dx.doi.org/10.1021/ac981329u

[12] Sun, Q., Chen, Y.F., Xu, D., Wang, Y. and Ding, S.M. (2013) Investigation of Potential Interferences on the Measurement of Dissolved Reactive Phosphate Using Zirconium Oxide-Based DGT Technique. Journal of Environmental Sciences, 25, 1592-1600. http://dx.doi.org/10.1016/S1001-0742(12)60140-5

[13] Pichette, C., Zhang, H., Davison, W. and Sauve, S. (2007) Preventing Biofilm Development on DGT Devices Using Metals and Antibiotic. Talanta, 72, 716-722. http://dx.doi.org/10.1016/j.talanta.2006.12.014

[14] Pichette, C., Zhang, H. and Sauve, S. (2009) Using Diffusive Gradients in Thin-Films for in Situ Monitoring of Dissolved Phosphate Emissions from Freshwater Aquaculture. Aquaculture, 286, 198-202. http://dx.doi.org/10.1016/j.aquaculture.2008.09.025

[15] Mengistu, H., Roeyset, O., Tessema, A., Abiye, T.A. and Demlie, M.B. (2012) Diffusive Gradient in Thin-Films (DGT) as Risk Assessment and Management Tools in the Central Witwatersrand Goldfield, South Africa. Water SA, 38, 15-22. http://dx.doi.org/10.4314/wsa.v38i1.3

[16] Agbenin, J.O. and Welp, G. (2012) Bioavailability of Copper, Cadmium, Zinc, and Lead in Tropical Savanna Soils Assessed by Diffusive Gradient in Thin Films (DGT) and Ion Exchange Resin Membranes. Environmental Monitoring and Assessment, 184, 2275-2284. http://dx.doi.org/10.1007/s10661-011-2116-5

[17] Roig, N., Nadal, M., Sierra, J., et al. (2011) Novel Approach for Assessing Heavy Metal Pollution and Ecotoxicoogical Status of Rivers by Means of Passive Sampling Methods. Environment International, 37, 671-677. http://dx.doi.org/10.1016/j.envint.2011.01.007

[18] Ekka, S.A., Haggard, B.E., Matlock, M.D. and Chaubey, I. (2006) Dissolved Phosphorus Concentrations and Sediment Interactions in Effluent-Dominated Ozark Streams. Ecological Engineering, 26, 375-391. http://dx.doi.org/10.1016/j.ecoleng.2006.01.002

[19] Zhang, L., Gu, X.Z., Fan, C.X., Shang, J.G., Shen, Q.S., Wang, Z.D. and Shen, J. (2010) Impact of Different Benthic Animals on Phosphorus Dynamics across the Sediment-Water Interface. Journal of Environmental Sciences, 22, 16741682. http://dx.doi.org/10.1016/S1001-0742(09)60305-3

[20] Ding, S.M., Xu, D., Sun, Q., Yin, H.B. and Zhang, C.S. (2010) Measurement of Dissolved Reactive Phosphorus Using the Diffusive Gradients in Thin Films Technique with a High-Capacity Binding Phase. Environmental Science and Technology, 44, 8169-8174. http://dx.doi.org/10.1021/es1020873

[21] Zan, F.Y., Huo, S.L., Xi, B.D., Zhu, C.W., Liao, H.Q., Zhang, J.T. and Yeager, K.M. (2012) A 100-Year Sedimentary Record of Natural and Anthropogenic Impacts on a Shallow Eutrophic Lake, Lake Chaohu, China. Journal of Environmental Monitoring, 14, 804-816. http://dx.doi.org/10.1039/c1em10760g

[22] Zan, F.Y., Huo, S.L., Xi, B.D., Li, Q.Q., Liao, H.Q. and Zhang, J.T. (2011) Phosphorus Distribution in the Sediments of a Shallow Eutrophic Lake, Lake Chaohu, China. Environmental Earth Sciences, 62, 1643-1653. http://dx.doi.org/10.1007/s12665-010-0649-5

[23] Zan, F.Y., Huo, S.L., Xi, B.D., Su, J., Li, X., Zhang, J.T. and Yeager, K.M. (2011) A 100 Year Sedimentary Record of Heavy Metal Pollution in a Shallow Eutrophic Lake, Lake Chaohu, China. Journal of Environmental Monitoring, 13, 2788-2797. http://dx.doi.org/10.1039/c1em10385g

[24] Huo, S.L., Zan, F.Y., Xi, B.D., Li, Q.Q. and Zhang, J.T. (2011) Phosphorus Fractionation in Different Trophic Sediments of Lakes from Different Regions, China. Journal of Environmental Monitoring, 13, 1088-1095. http://dx.doi.org/10.1039/c0em00696c

[25] Zhang, H. and Davison, W. (1995) Performance Characteristics of Diffusion Gradients in Thin Films for the in Situ Measurement of Trace Metals in Aqueous Solution. Analytical Chemistry, 67, 3391-3400. http://dx.doi.org/10.1021/ac00115a005

[26] Wu, Z.H., He, M.C. and Lin, C.Y. (2011) In Situ Measurements of Concentrations of Cd, Co, Fe and Mn in Estuarine 
Porewater Using DGT. Environmental Pollution, 159, 1123-1128. http://dx.doi.org/10.1016/j.envpol.2011.02.015

[27] Harper, M.P., Davison, W. and Tych, W. (1997) Temporal, Spatial and Resolution Constraints for in Situ Sampling Devices Using Diffusional Equilibration: Dialysis and DET. Environmental Science and Technology, 31, 3110-3119. http://dx.doi.org/10.1021/es9700515

[28] Harper, M.P., Davison, W. and Tych, W. (1999) Estimation of Pore Water Concentrations from DGT Profiles: A Modelling Approach. Aquatic Geochemistry, 5, 337-355. http://dx.doi.org/10.1023/A:1009620412373

[29] Harper, M.P., Davison, W. and Tych, W. (1999) One Dimensional Views of Three Dimensional Sediments. Environmental Science and Technology, 33, 2611-2616. http://dx.doi.org/10.1021/es9900813

[30] Cha, H.J., Lee, C.B., Kim, B.S., Choi, M.S. and Ruttenberg, K.C. (2005) Early Diagenetic Redistribution and Burial of Phosphorus in the Sediments of the Southwestern East Sea (Japan Sea). Marine Geology, 216, 127-143. http://dx.doi.org/10.1016/j.margeo.2005.02.001

[31] Mayer, T., Ptacek, C. and Zanini, L. (1999) Sediment as a Source of Nutrients to Hypereutropic Marshes of Point Pelee, Ontario, Canada. Water Research, 33, 1460-1470. http://dx.doi.org/10.1016/S0043-1354(98)00348-0

[32] Maher, W. and Woo, L. (1998) Procedures for the Storage and Digestion of Natural Waters for the Determination of Filterable Reactive Phosphorus, Total Filterable Phosphorus and Total Phosphorus. Analytica Chimica Acta, 375, 5-47. http://dx.doi.org/10.1016/S0003-2670(98)00274-8

[33] Zhang, R.Y., Wu, F.C., He, Z.Q., Zheng, J., Song, B.A. and Jin, L.H. (2009) Phosphorus Composition in Sediments from Seven Different Trophic Lakes, China: A Phosphorus-31 NMR Study. Journal of Environmental Quality, 38, 353-359. http://dx.doi.org/10.2134/jeq2007.0616

[34] Lesven, L., Gao, Y., Billon, G., Leermakers, M., Ouddane, B., Fischer, J.C. and Baeyens, W. (2008) Early Diagenetic Processes Aspects Controlling the Mobility of Dissolved Trace Metals in Three Riverine Sediment Columns. Science of the Total Environment, 407, 447-459. http://dx.doi.org/10.1016/j.scitotenv.2008.08.033

[35] Zhang, H., Davison, W., Miller, S. and Tych, W. (1995) In Situ High Resolution Measurements of Fluxes of Ni, Cu, Fe, and $\mathrm{Mn}$ and Concentrations of Zn and Cd in Porewaters by DGT. Geochimica et Cosmochimica Acta, 59, 4181-4192. http://dx.doi.org/10.1016/0016-7037(95)00293-9

[36] Alexa, N., Zhang, H. and Lead, J.R. (2009) Development of a Miniaturized Diffusive Gradients in Thin Films (DGT) Device. Analytica Chimica Acta, 655, 80-85. http://dx.doi.org/10.1016/j.aca.2009.09.046

[37] Garmo, Q.A., Naqvi, K.R., Røyset, O. and Steinnes, R.E. (2006) Estimation of Diffusive Boundary Layer Thickness in Studies Involving Diffusive Gradients in Thin Films (DGT). Analytical and Bioanalytical Chemistry, 386, 2233-2237. http://dx.doi.org/10.1007/s00216-006-0885-4

[38] Warnken, K.W., Zhang, H. and Davison, W. (2006) Accuracy of the Diffusive Gradients in Thin-Films Technique: Diffusive Boundary Layer and Effective Sampling Area Considerations. Analatical Chemistry, 78, 3780-3787. http://dx.doi.org/10.1021/ac060139d 